\title{
Exogenous Application of Plant Growth Regulators Induce Chilling Tolerance in Direct Seeded Super and Non-super Rice Seedlings through Modulations in Morpho-physiological Attributes
}

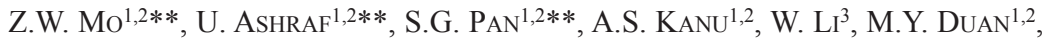 \\ H. TIAN ${ }^{1,2}$ and X.R. TANG ${ }^{1,2 *}$ \\ ${ }^{1}$ Department of Crop Science and Technology, College of Agriculture, South China Agricultural University, \\ Guangzhou 510642, PR China \\ ${ }^{2}$ Scientific Observing and Experimental Station of Crop cultivation in South China, Ministry of Agriculture, \\ P.R. China, Guangzhou, 510642 China \\ ${ }^{3}$ Crops Research Institute, Guangdong Academy of Agricultural Sciences, Guangzhou, \\ Guangdong 510640, PR China \\ (Received 1 November 2015; Accepted 16 December 2015; \\ Communicated by J. Kubat)
}

\begin{abstract}
Recently, super rice has gained much importance due to its high yield potential while exogenous application of plant growth regulators (PGRs) is an important aspect in plant development and defense responses under stress conditions. In this study we conducted two pot experiments. Firstly, four super rice cultivars, viz. Peizataifeng, Huayou 213, Yuxiangyouzhan and Huahang 31 were subjected to a series of five chilling temperatures, i.e. $11^{\circ} \mathrm{C}, 12{ }^{\circ} \mathrm{C}, 13{ }^{\circ} \mathrm{C}, 14{ }^{\circ} \mathrm{C}$ and $15{ }^{\circ} \mathrm{C}$ (day/night) for about $25-27$ days. Secondly, seeds of Peizataifeng (super rice) and Yuejingsimiao 2 (non-super rice) were then treated with different combinations of salicylic acid (SA), brassinolide (BR), calcium chloride $\left(\mathrm{CaCl}_{2}\right)$ and fulvic acid (FA) and then exposed to chilling stress at $13{ }^{\circ} \mathrm{C}$ for four days. Resultantly, Peizataifen (super rice) was found with the lowest seedling survival rate at all chilling temperatures among all four super rice cultivars, however, it was still found more resistant when compared with Yuejingsimiao 2 (non-super rice) in the second experiment. Furthermore synergistic effect of all PGRs alleviated low temperature stress in both rice cultivars by improving seedling survival rates, leaf area, seedling dry weight, seedling height, root morphology and by modulating antioxidant enzymes, improving proline content and lowering lipid peroxidation.
\end{abstract}

Keywords: antioxidant enzymes, chilling stress, rice seedlings, survival rates

Abbreviations: DWSH - Dry weight per unit seedling height; LA - Leaf area; MDA Malondialdehyde content; POD - Per-oxidase activity; PGRs - Plant growth regulators; Pro - Proline content; RAD - Root average diameter; RV - Root volume; RL - Root length; RSA - Root surface area; SR - Survival rate; SDW - Shoot dry weight; SH - Seedling height; SOD - Super oxide dismutase activity.

\footnotetext{
*Corresponding author; E-mail: tangxr@scau.edu.cn; Phone/Fax: 020-85280204-618

**These authors have contributed equally to this work.
} 


\section{Introduction}

Rice (Oryza sativa L.) is one of the most important staple food, feeding almost 3 billion people over the world with annual production of $700 \mathrm{Mt}$. China and India are the major countries where more than $90 \%$ of the rice is produced and consumed (Pathak et al. 2011). However its production through conventional puddled rice system is facing severe management, financial and socio-economic constraints. Impeding water scarcity, intensive labor and water requirements had pushed the scientist to develop alternative rice cultivation methods to enhance resource attribution with low environmental risks. Direct seeded rice (DSR) has gained much importance as an alternative method of rice production with low input demands (Farooq et al. 2011).

Overall, China is the largest producer and consumer of rice worldwide where rice is cultivated under a wide range of climate with higher spatial and temporal variability. Super rice, developed with the combine efforts of International Rice Research Institute (IRRI) and other Asian countries like China, Korea and Japan, has gained much importance due to its high yield potential (Amano et al. 1996). China has already established mega-projects on its multiplication and development to encounter the food challenges in future. For instance, from 1996 to 2012 China has released 96 cultivars of super rice that are grown successfully over a wide range of climate throughout China over an area of about $80 \mathrm{~m}$ ha (Cheng et al. 2013).

Low temperature is one of the unfavorable conditions in rice that limits its growth, survival rate, distribution and overall productivity (Han et al. 2006). The optimum growth temperatures for rice are between 25 and $30^{\circ} \mathrm{C}$ while the lower critical temperature at the germination stage is $10{ }^{\circ} \mathrm{C}$ (Yoshida 1981). Low temperatures can cause low germination rate and reduces seedling vigor especially temperature below $15^{\circ} \mathrm{C}$ at seedling stage usually results in poor seedling establishment or seedling mortality (Jiang et al. 2008). The effect of cold tolerance on rice germination and seedlings development were previously determined at various lower temperatures, such as $13{ }^{\circ} \mathrm{C}$ (Cruz and Milach 2004); 10, 13, and $15^{\circ} \mathrm{C}$ (Baruah et al. 2009); and 13 and $17^{\circ} \mathrm{C}$ (Sharifi and Aminpanah 2010). A wide range of temperature needs to be examined for evaluating the critical temperature of direct seeded rice germination.

Plant growth regulators (PGRs) either natural or synthetic, are extensively applied (foliar or through seed treatments) to agricultural crops to induce abiotic stress tolerance (Kader and Lindberg 2010). PGRs acclimatize plant growth and development under stress conditions in various ways. Calcium chloride, humic substances (fulvic acid and humic acid), salicylic acid and brassinosteroids are considered as plant endogenous regulators involved in defending against chilling stress (Shah 2003; White and Broadley 2003). Application of PGRs enhanced plant resistance to different biotic and abiotic stresses by manipulating various physiological and biochemical mechanisms (Anjum et al. 2011a). For example exogenous application of brassinosteroids induced osmotic stress tolerance in sorghum through modulation of antioxidant enzyme system (Vardhini and Rao 2003). PGRs-induced improvements against abiotic stresses are strongly linked to improved physiological responses in plants (Walia et al. 2007). 
Individual or separate application of different PGRs induced modulations in plant response to various abiotic stresses has been widely reported (Kader et al. 2007; Anjum et al. 2011b), however, their integrated application and eventual effects on germination behavior and seedling development of direct seeded super and non-super rice under low temperature is still elusive. This study was therefore designed with the objectives of investigating the germination potential and relative performance of direct seeded super and non-super rice seedlings under low temperature $\left(11^{\circ} \mathrm{C}\right.$ to $\left.15^{\circ} \mathrm{C}\right)$ to find out the critical temperature for rice seed germination and to study the possible roles of PGRs in stress alleviation.

\section{Materials and Methods}

\section{Plant material}

Seeds of both super and non-super rice were collected form College of Agriculture, South China Agricultural University, Gangzhou, China. Before sowing, seeds were surface sterilized with sodium hypochlorite solution $(0.5 \%(\mathrm{v} / \mathrm{v})$ for $20 \mathrm{~min}$, then washed thoroughly with double distilled water then with deionized water. The seeds were then soaked in distilled water for $24 \mathrm{~h}$, and later transferred to beakers covered with wet paper, for next $24 \mathrm{~h}$ at $30{ }^{\circ} \mathrm{C}$ in a dark chamber. The 100 uniform seeds were sown in plastic pots $(18$ $\mathrm{cm} \times 13 \mathrm{~cm} \times 6 \mathrm{~cm}$ ) containing about $4.5 \mathrm{~cm}$ depth of sandy loam soil containing organic matter $19.65 \mathrm{mg} \mathrm{kg}^{-1}$, total nitrogen $0.97 \mathrm{~g} \mathrm{~kg}^{-1}$, total phosphorous $0.82 \mathrm{~g} \mathrm{~kg}^{-1}$, total potassium $25.50 \mathrm{~g} \mathrm{~kg}^{-1}$ and $\mathrm{pH} 5.44$.

\section{Experimentation}

\section{Experiment 1}

Four super rice cultivars, viz. Peizataifeng, Huayou 213, Yuxiangyouzhan and Huahang 31 were sown in plastic pots and subjected to a series of five chilling treatments, i.e. $11{ }^{\circ} \mathrm{C}, 12{ }^{\circ} \mathrm{C}, 13{ }^{\circ} \mathrm{C}, 14^{\circ} \mathrm{C}$ and $15{ }^{\circ} \mathrm{C}$ (day/night temperature) for 25 days. The varieties used in this study are popular varieties in Guangdong region rice double cropping system. Survival rates (SR) of rice plumule for these four varieties were calculated after 4, 7, 10, 13, 16, 19, 22 and 25 days after sowing by using the following formula: (survived plumule/seed number $) \times 100$. Among these four super rice verities; Peizataifeng was found the most sensitive to the chilling temperature (data shown in Fig. S1*), so we used it for our experiment 2 to compare it with a non-super rice verity Yuejingsimiao 2 to evaluate the relative performance of super and non-super rice seedlings at chilling temperature.

\section{Experiment 2}

In this experiment, seeds of Peizataifeng (super rice) and Yuejingsimiao 2 (non-super rice) were then sown in plastic pots containing similar type of soil and transferred to growth

*Further details about the Electronic Supplementary Material (ESM) can be found at the end of the article. 
chamber (PGX-600A-3HR, Zhejiang, China) under standard conditions (12 h photo-period at $150-200 \mu \mathrm{mol} \mathrm{m} \mathrm{m}^{-2} \mathrm{~s}^{-1}, 28 / 22^{\circ} \mathrm{C}$ day/night temperature and $70 \% \mathrm{RH}$ ) till second leaf stage, then different plant growth were exogenously applied in the following concentration: $(\mathrm{T} 1)=$ salicylic acid $(\mathrm{mmol} / \mathrm{L})$ : brassinolide $(\mathrm{mg} / \mathrm{L})$ : calcium chloride $(\mathrm{mmol} / \mathrm{L})$ : fulvic acid $(\mathrm{g} / \mathrm{L})=1: 2: 1: 2,(\mathrm{~T} 2)=$ salicylic acid $(\mathrm{mmol} / \mathrm{L}):$ brassinolide $(\mathrm{mg} / \mathrm{L}):$ calcium chloride $(\mathrm{mmol} / \mathrm{L})$ : fulvic acid $(\mathrm{g} / \mathrm{L})=2: 2: 1: 2,(\mathrm{~T} 3)=$ salicylic acid $(\mathrm{mmol} / \mathrm{L})$ : brassinolide $(\mathrm{mg} / \mathrm{L})$ : calcium chloride $(\mathrm{mmol} / \mathrm{L})$ : fulvic acid $(\mathrm{g} / \mathrm{L})=3: 2: 1: 2$. Distilled water was sprayed in control pots $(\mathrm{CK})$. After spraying, plants were immediately exposed to chilling stress at $13{ }^{\circ} \mathrm{C}$ for four days then allowed to recover for three days.

\section{Data recording}

Seedling survival rate and plant morphology

Total number of rice seedlings and number of survived seedlings were counted before and after chilling treatment to count the seedling survival rate (SR) \% which is calculated as: (survived seedlings after treatment $/$ total rice seedlings before treatment) $\times 100$. Seedling height (SH) was measured using a ruler from thirty randomly selected rice plants. Twenty plants were randomly selected from each plot, and divided into leaves, stems and roots to measure leaf area (LA), root morphology and shoot dry weight (SDW). Leaf area was measured by a leaf area meter (CI-202 Area Meter, CID, Inc.). Dry weight per unit seedling height (DWSH) was calculated as: (shoot dry weight / plant height) and expressed as micrograms per centimeter $\left(\mu \mathrm{g} \mathrm{cm}^{-1}\right)$.

\section{Physiological indices}

Plants from each treatments were sampled and frozen in liquid nitrogen and kept at $-80{ }^{\circ} \mathrm{C}$ and later processed for analyses for physiological characteristics, i.e. super-oxide dismutase (SOD), peroxidase (POD) and malondialdehyde (MDA). SOD activity was determined based on the method of Beyer and Fridovich (1987) with some modifications. Leaf $(0.3 \mathrm{~g})$ was homogenized with $5 \mathrm{ml}$ of $50 \mathrm{mM}$ phosphate buffer $(\mathrm{pH} 7.8)$ containing $100 \mu \mathrm{mmol} / \mathrm{L}$ EDTA-Na ${ }_{2}$. The homogenate was centrifuged at $12000 \mathrm{rpm}$ for $15 \mathrm{~min}$ at $4{ }^{\circ} \mathrm{C}$ and the supernatant was immediately used for the enzyme assay. The reaction mixture was composed of $1.5 \mathrm{ml}$ of $50 \mathrm{mmol} / \mathrm{L}$ potassium phosphate $(\mathrm{pH} 7.8), 0.3 \mathrm{ml}$ of 100 $\mu \mathrm{mmol} / \mathrm{L}$ EDTA-Na ${ }_{2}, 0.3 \mathrm{ml}$ of $13 \mathrm{mmol} / \mathrm{L}$ methionine, $0.3 \mathrm{ml}$ of $75 \mu \mathrm{mol} / \mathrm{L} \mathrm{NBT}, 0.3 \mathrm{ml}$ of $2 \mu \mathrm{mol} / \mathrm{L}$ riboflavin and $50 \mu \mathrm{l}$ of plant extract. The reaction was initiated by light illumination. One unit of SOD was defined as the amount of an enzyme necessary to produce a $50 \%$ inhibition of the maximum value of inhibition. The activity was expressed as $\mathrm{U} / \mathrm{g}$ fresh weight.

The peroxidase (POD) activity was measured using the method described by Fang and Kao (2000) with some modifications. Leaf $(0.25 \mathrm{~g})$ was homogenized with $4 \mathrm{ml}$ of 50 $\mathrm{mM}$ sodium phosphate buffer $(\mathrm{pH} 7.0)$. The homogenate was centrifuged at $12000 \mathrm{rpm}$ for $15 \mathrm{~min}$ at $4{ }^{\circ} \mathrm{C}$ and the supernatant was used for determination of POD activity. POD activity was measured in a reaction mixture $(3 \mathrm{ml})$ that contained $50 \mu \mathrm{l}$ enzyme extract, 
$1 \mathrm{ml}$ of $0.2 \% \mathrm{H}_{2} \mathrm{O}_{2}$, and $950 \mu \mathrm{l}$ of $0.2 \%$ guaiacol in $50 \mathrm{mM}$ phosphate buffer $(\mathrm{pH} 7.0)$ and $1 \mathrm{ml}$ of $50 \mathrm{mM}$ sodium phosphate buffer $(\mathrm{pH} 7.0)$. Absorbance change of the brown guaiacol at $470 \mathrm{~nm}$ was recorded for calculating POD activity. One unit of POD activity was defined as oxidation of 1 unit guaiacol per minute. Activity was calculated and expressed as units per gram of fresh weight (FW).

Malondialdehyde (MDA) content was measured by following protocols devised by Chen and Wang (2006) to measure the MDA contents. Leaf $(0.5 \mathrm{~g})$ was homogenized with $5 \mathrm{ml}$ of $10 \%$ trichloroacetic acid (TCA) and centrifuged at $12000 \mathrm{rpm}$ for $10 \mathrm{~min}$. After centrifugation, two $\mathrm{ml}$ supernatant was mixed with the same volume of a $0.5 \%$ thiobarbituric acid solution containing $10 \%$ (w: v) trichloroacetic acid. The mixture was immediately heated at $99^{\circ} \mathrm{C}$ for $20 \mathrm{~min}$ and the reaction was stopped by quickly placing in an ice bath. The cooled mixture was then centrifuged at $12000 \mathrm{rmp}$ for $10 \mathrm{~min}$, and the absorbance of the supernatant at $532 \mathrm{~nm}, 600 \mathrm{~nm}$ and $450 \mathrm{~nm}$ was recorded and expressed as $\mu \mathrm{mol} / \mathrm{g} \mathrm{FW}$.

The proline content was determined according to the method described by Bates et al. (1973). Briefly, leaves $(0.2 \mathrm{~g})$ were homogenized in $5 \mathrm{ml}$ of $3 \%$ sulfosalicylic acid, then cooled after heating at $99{ }^{\circ} \mathrm{C}$ for $10 \mathrm{~min}$. After heated, filtrated and then absorb two $\mathrm{ml}$ of filtrate, and then mixed with $3 \mathrm{ml}$ of ninhydrin reagent $(1.25 \mathrm{~g}$ ninhydrin in $30 \mathrm{ml}$ glacial acetic acid and $20 \mathrm{ml} 6 \mathrm{M}$ phosphoric acid) and $2 \mathrm{ml}$ of glacial acetic acid. The reaction mixture was then heated at $99^{\circ} \mathrm{C}$ for $40 \mathrm{~min}$ and then cooled for $20 \mathrm{~min}$ before being extracted with $4 \mathrm{ml}$ of toluene and centrifuged at $4000 \mathrm{rpm}$ for $5 \mathrm{~min}$. The absorbance of the red chromophore in the toluene fraction was measured at $520 \mathrm{~nm}$ and the amount of proline was determined by comparison with a standard curve and expressed as $\mu \mathrm{g} / \mathrm{g} \mathrm{FW}$.

\section{Experimental design and statistical analysis}

The experiment was performed in a completely randomized design (CRD) with three replicates. Data presented here are the means of three replicates for each treatment. Analyses of variances (ANOVA) were performed by the Linear Model Procedure of Statistix statistical software version 8 (Statistix 8, Analytical, Tallahassee, Florida, USA). ANOVA was used to determine the treatment effects on each variable and confidence intervals derived from these analyses were used to establish significant effects. Comparisons of means among different treatments were done according to the least significant difference (LSD) at the 5\% probability level. Principal component analysis was done with XLSTAT software (MacOS ed. Paris, France).

\section{Results}

\section{Experiment 1}

Survival rate of rice plumule under different chilling-stress conditions

Survival rates of rice plumule under different chilling stress conditions $11^{\circ} \mathrm{C}, 12{ }^{\circ} \mathrm{C}$, $13{ }^{\circ} \mathrm{C}, 14{ }^{\circ} \mathrm{C}$ and $15{ }^{\circ} \mathrm{C}$ were shown in Fig. S1 (A-E). Average survival rates of both super and non-super rice plumule under continued chilling stress of 25-27 days were $14.58 \%$, 
$38.45 \%, 60.67 \%, 77.00 \%$ and $92.58 \%$ in $11^{\circ} \mathrm{C}, 12{ }^{\circ} \mathrm{C}, 13{ }^{\circ} \mathrm{C}, 14^{\circ} \mathrm{C}$ and $15^{\circ} \mathrm{C}$, respectively. Regarding varieties, Peizataifeng had the lowest survival rates than other varieties under all the chilling stress conditions whereas Huayou 213 had highest survival rates at low $\left(11^{\circ} \mathrm{C}\right.$ and $\left.12{ }^{\circ} \mathrm{C}\right)$ and medium temperature $\left(13{ }^{\circ} \mathrm{C}\right)$ (Fig. S1 A-C) while at high temperature $\left(14^{\circ} \mathrm{C}\right.$ and $\left.15^{\circ} \mathrm{C}\right)$, highest survival rates were observed in Yuxiangyouzhan (Fig. S1 D-E). In respect to peak survival rates, the highest survival rates of all varieties growing under chilling condition were observed approximately on the $10^{\text {th }}$ day after sowing. Overall, seed survival rates increased linearly with respect to increase temperature in with maximum at $15^{\circ} \mathrm{C}$ with highest in Yuxiangyouzhan while lowest in Peizataifeng. Furthermore, an abrupt decrease in seed survival rates after temperatures lower than $13{ }^{\circ} \mathrm{C}$ indicated it as a critical temperature for super rice seedling growth.

\section{Experiment 2}

Analysis of variance (F-value) for the investigated parameters

Analysis of variance (F-value) for the investigated parameters showed that shoot dry weight, seedling height, dry weight per unit seedling height, root length, root surface area, peroxidase activity, and malondialdehyde content varied significantly $(\mathrm{P} \leq 0.05)$ with respect to variety sown while a significant effect of chilling treatment was also prominent on all the investigated parameters, except for root length. Moreover, interaction of variety and temperature $(\mathrm{V} \times \mathrm{T})$ had significant effects on seedling height, root surface area, and peroxidase activity (Table $\mathrm{S} 1)$.

\section{Seedling survival rate, and shoot and root morphology}

Application of PGRs before chilling stress stimulated seedling growth in terms of SR, LA, SDW, DWSH and root morphological attributes under chilling stress conditions in both varieties, i.e. Yuejingsimiao 2 and Pezataifeng (Table S2). PGRs improved SH and the highest increase was observed in Peizataifeng in T3. Further, PGRs induced remarkable increase in SR, LA, SDW over control in Yuejingsimiao 2; whereas SH and DWSH were significantly $(\mathrm{P} \leq 0.05)$ increased in Yuejingsimiao 2 in the treatments $(\mathrm{T} 2$ and T3) and (T1 and T2), respectively. In Peizataifeng, T1 and T3 notably increased SR as compared with control. A substantial increase in both LA and SH were also observed in T3 as compared to CK, however, highest SDW and DWSH was observed in T2. In respect of varieties, on an average, higher SR, LA, SDW and SH were observed in Peizataifeng than in Yuejingsimiao 2; however, lower DWSH were observed in Peizataifeng than Yuejingsimiao 2. Across treatment and varieties, SR and other growth parameters were found highest in Peizataifeng sprayed with PGRs, except for DWS, which was higher in Yuejingsimiao 2 sprayed with T2, while the lowest SR and growth parameters were observed in Yuejingsimiao 2 in control (CK).

Furthermore, for Yuejingsimiao 2, compared with control, application of PGRs increased RSA considerably while a highly significant increase in RAD was observed in T3. Furthermore, except RAD, all other root morphological parameters were significantly 
improved in T1 over CK in Peizataifeng. T3 showed notably higher RSA as compared to CK. Regarding varieties, on an average, increased root morphological parameters (except RAD), e.g. RL, RSA and RV were observed in Peizataifeng after spraying with T1. The minimum values for root morphological parameters were observed in Yuejisimiao in control.

\section{Physiological indices}

The increased growth in rice seedlings by the PGRs under chilling stress conditions was associated with enhanced levels of proline content and antioxidant enzymes (SOD and POD) activity, decreased MDA content in both varieties Peizataifeng and Yuejingsimiao 2 (Fig. S2 A-D). Interactive effect of treatments and variety $(\mathrm{T} \times \mathrm{V})$ depicted that maximum SOD and POD activities were found in Yuejingsimiao 2 under T1 conditions whereas MDA and proline contents were higher in CK followed by T2. Improved POD activity in T1, SOD and proline contents in T2 were observed in Peizataifeng while enhanced MDA levels were noted in control.

\section{Correlation coefficients among the investigated parameters}

SR has significant positive correlations with LA, SDW, RSA, RAD, and RV while negatively with MDA contents. Similarly, LA and SDW are positively correlated with SDW, SH, RAD, RV and with DWSH and proline, respectively, while DWSH had significant correlation with SOD, POD, and proline but negatively, with MDA contents. Similarly, RV and RSA are also positively correlated with RL whereas RSA also had significant positive correlation with RAD and RV which are also positively correlated with each other. Additionally, significant positive correlation between POD and Pro was also found. Except SOD and POD, all other parameters are negatively correlated with MDA contents (Table S3).

\section{Principal component analysis for the investigated parameters}

Table S4 indicated that the first four factors capturing $81.128 \%$ of the information: $35.223 \%, 23.484 \%, 13.312 \%$, and $9.109 \%$ by F1, F2, F3 and F4, respectively. Further, SR, LA, SDW, RL, RSA, RV, and MDA contributed most for F1. For F2, SH, DWSH, SOD, POD and Pro contributed the most while RAD contributed the most for F4.

\section{Discussion}

The present study was conducted to explore the germination potential of direct seeded super and non-super rice and stress alleviatory roles of PGRs under chilling stress. In this study we have found that temperature below $15{ }^{\circ} \mathrm{C}$ reduced rice final plumule survival rates (Fig. S1 A-E). In general, low temperature in rice at earlier stages retards seed germination and seedling growth; results in poor stand establishment, leaf discoloration and 
inhibited vegetative growth (Kaneda and Beachell 1974). Our findings corroborates with Farrell et al. (2006) who regarded 13 and $15^{\circ} \mathrm{C}$ temperature as the threshold nightly temperature for cold-tolerant and cold sensitive rice cultivars, respectively, that might induce cold damage. We further found similar trends in survival rates under the five continuing low temperature treatments, and the trend followed a pattern in which: survival rates were first increased, and at about the $10^{\text {th }}$ day reached their peak, and then decreased; the decreasing of survival rates became less with the increase in temperature (from 11 to $15{ }^{\circ} \mathrm{C}$ ).

Calcium chloride, humic substances, salicylic acid and brassinosteroids are considered as plant endogenous regulators in defending stress (Kader et al. 2007; Kader and Lindberg 2010). Brassinosteroids, well-known natural substances which modulate plant growth by improving its tolerance under stress (Anjum et al. 2011b). Brassinosteroids induced chilling tolerance in rice seedlings and improved overall growth and total biomass accumulation under low temperature conditions (Wang and Zeng 1992). On the other hand, spraying with $0.005 \mathrm{mg} / \mathrm{L}$ of brassinolide protected the rice seedlings from heat stress (Cao and Zhao 2008). Calcium chloride act as a plat growth regulator due to release of $\mathrm{Ca}^{2+}$ ions that act as a ubiquitous secondary messenger that mediates plant growth and development under stress conditions (Kader and Lindberg 2010; White and Broadley 2003). Moreover, humic substances have also been reported to regulate plant growth under abiotic stress conditions. For example, foliar application of FA $(1.5 \mathrm{mg} / \mathrm{L})$ substantially ameliorated the adversities of drought by enhanced levels of antioxidant enzymes (superoxide dismutase (SOD), peroxidase (POD), and catalase (CAT) activities and proline) (Anjum et al. 2011a). Furthermore, salicylic acid is considered as an endogenous regulator, has long been known as a signal molecule in the induction of defense mechanisms in plants (Shah 2003) and plays an important role in defending biotic and abiotic stresses in plants, because it has been qualified as a plant hormone due to its physiological and biological roles (Pan et al. 2013). Salicylic acid-induced improvements in rice seedling growth, biomass accumulation and antioxidant activity at low temperature were also reported by Pouramir-Dashtmiana et al. (2014).

Chilling stress triggered the lipid peroxidation processes thus resulted in greater accumulation in MDA contents while application of PGRs reduced destructive mechanism by increasing activities of enzymatic antioxidants (SOD and POD) and proline accumulation under chilling stress (Fig. S2 A-D). In our study, reduced MDA contents due to application of PGRs indicated their ability to quench free radicles and protection potential against ROS activities and lipid peroxidation. We further noticed that mixtures of salicylic acid, brassinolide, calcium chloride and fulvic acid increased the seedling survival rates, leaf area, shoot dry weight, and dry weight per unit seedling height, root morphology parameters (Table S2). Antioxidants (both SOD and POD) take a concerted action against oxidative damage by scavenging the ROS. SOD reduced $\mathrm{O}_{2}-$ to $\mathrm{H}_{2} \mathrm{O}_{2}$ that is further reduced to $\mathrm{H}_{2} \mathrm{O}$ by POD. Improved antioxidative activities and reduced destructive mechanism due to exogenous feeding of PGRs in rice were also confirmed from the previous literature (Peng et al. 2011; Zheng et al. 2011; Pan et al. 2013). On the other hand, coalesced responses of SOD and CAT have a substantial impact on seedling growth and development (Yang et al. 2001). This transient increase in antioxidant enzyme activity 
under chilling stress might protect the rice seedlings from oxidative damage. Moreover, modulation in antioxidant enzymatic activity seems the outcomes of PGRs-induced regulation of transcription and translation processes that improved total proteins contents and antioxidants while reduced lipid peroxidation (Bajguz 2000).

Additionally, significant positive correlation was observed between different morphological parameters except MDA which showed negative correlations with and SR, LA, $\mathrm{SH}$, and RAD (Table S3). Furthermore, results indicated that the first four factors capturing $81.13 \%$ of the information: $35.22 \%, 23.48 \%, 13.31 \%$, and $9.11 \%$ by F1, F2, F3 and F4, respectively, on one hand while SR, LA, SDW, RL, RSA, RV, and MDA made maximum contributions for F1 whereas SH, DWSH, SOD, POD and Pro for F2 and RAD imparted maximum for F4 (Table S4). Thus, we confirmed that the investigated parameters were considered as characters that reflected the seedling's response to chilling after spraying with PGRs. Indeed, the stress alleviation role of PGRs and their synergistic effects on rice seedlings to induce chilling tolerance might be sufficient to sustain early stand establishment in direct seeded rice. Nonetheless, to declare threshold temperature limits for seed germination for a diverse group of rice genotypes further research needed, whereas exogenous application of PGRs at earlier growth stages can be the best strategy to induce chilling tolerance in developing rice seedlings.

In crux, average survival rates of rice seedlings under continued chilling stress at $13{ }^{\circ} \mathrm{C}$ for 25-27 days were remained about $60 \%$. Synergistic effects of PGRs improved rice seedling growth by modulating antioxidative defense activities, osmolyte accumulation and reducing MDA production. Interestingly, non-super rice seedlings was found chilling sensitive than super rice seedlings; besides, $13{ }^{\circ} \mathrm{C}$ was found as critical temperature for seed germination of super rice. Further, information about the mechanisms of PGRs to induce chilling tolerance in diverse group of plant species are still limited that must be further studied.

\section{Conflict of Interest}

The authors declare that there is no conflict of interest.

\section{Acknowledgements}

Appreciation to Guangdong Province production and research subproject (2011AO20202001) and funds for breeding new rice varieties and supporting technology extension in Guangdong Province in 2010 (2010.01-2011.12) are highly acknowledged for their numerous support in the research.

\section{References}

Amano, T., Shi, C., Qin, D., Tsuda, M.Y.M. 1996. High yielding performance of paddy rice achieved in Yunnan Province, China: I. High yielding ability of japonica F1 hybrid rice, Yu-Za 29. Jpn. J. Crop Sci. 65:16-21.

Anjum, S.A., Wang, L.C., Farooq, M., Xue, L., Ali, S. 2011a. Fulvic acid application improves the maize performance under well-watered and drought conditions. J. Agron. Crop Sci. 197:409-417. 
Anjum, S.A., Wang, L.C., Farooq, M., Hussain, M., Xue, L.L., Zou, C.M. 2011b. Brassinolide application improves the drought tolerance in maize through modulation of enzymatic antioxidants and leaf gas exchange. J. Agron. Crop Sci. 197:177-185.

Bajguz, A. 2000. Effect of brassinosteroids on nucleic acid and protein content in cultured cells of Chlorella vulgaris. Plant. Physiol. Biochem. 38:209-215.

Baruah, A., Ishigo-Oka, N., Adachi, M., Oguma, Y., Tokizono, Y., Onishi, K., Sano, Y. 2009. Cold tolerance at the early growth stage in wild and cultivated rice. Euphytica 165:459-470.

Bates, L.S., Waldron, R.P., Teare, I.D. 1973. Rapid determination of free proline for water stress studies. Plant and Soil 39:205-208.

Beyer, W.F., Fridovich, I. 1987. Assaying for superoxide dismutase activity: some large consequences of minor changes in conditions. Anal. Biochem. 161:559-566.

Cao, Y.Y., Zhao, H. 2008. Protective roles of brassinolide on rice seedlings under high temperature stress. Rice Sci. 15:63-68.

Chen, J.X., Wang, X.F. 2006. Experimental Guide of Plant Physiology. $2^{\text {nd }}$ ed. Guangzhou: South China University of Technology Press. Guangzhou-China. (in Chinese)

Cheng, S.H., Fang, F.P., Zhu, Z.W., Zhu, D., Xiang, J. 2013. Reports on China's rice production, China National Rice Research Institution. Beijing, China, 33 p.

Cruz, R., Milach, S. 2004. Cold tolerance at the germination stage of rice: methods of evaluation and characterization of genotypes. Sci. Agric. 61:1-8.

Fang, W.C., Kao, C.H. 2000. Enhanced peroxidase activity in rice leaves in response to excess iron, copper and zinc. Plant Sci. 158:71-76.

Farooq, M., Siddique, K.H.M., Rehman, H., Aziz, T., Lee, D.J., Wahid, A. 2011. Rice direct seeding: Experiences, challenges and opportunities. Soil Till. Res. 111:87-98.

Farrell, T.C., Fox, K.M., Williams, R.L., Fukai, S. 2006. Genotypic variation for cold tolerance during reproductive development in rice: screening with cold air and cold water. Field Crops Res. 98:178-194.

Han, L.Z., Zhang, Y.Y., Qiao, Y.L., Cao, G.L., Zhang, S.Y., Kim, J.H., Koh, H.J. 2006. Genetic and QTL analysis for low-temperature vigour of germination in rice. Acta Genetica Sinica 33:998-1006.

Jiang, L., Xun, M.M., Wang, J.L., Wan, J.M. 2008. QTL analysis of cold tolerance at seedling stage in rice (Oryza sativa L.) using recombination inbred lines. J. Cereal Sci. 48:173-179.

Kader, M.A., Lindberg, S., Seidel, T., Golldack, D., Yemelyanov, V. 2007. Sodium sensing induces different changes in free cytosolic calcium concentration and $\mathrm{pH}$ in salt-tolerant and sensitive rice (Oryza sativa) cultivars. Physiol. Plantarum 130:99-111.

Kader, M.A., Lindberg, S. 2010. Cytosolic calcium and $\mathrm{pH}$ signaling in plants under salinity stress. Plant Signal. Behav. 5:233-238.

Kaneda, C., Beachell, H.M. 1974. Response of indica-japonica rice hybrids to low temperatures. SABRO J. 1:17-32.

Pan, S., Rasul, F., Li, W., Tian, H., Mo, Z., Duan, M., Tang, X.R. 2013. Roles of plant growth regulators on yield, grain qualities and antioxidant enzyme activities in super hybrid rice (Oryza sativa L.). Rice 6:9.

Pathak, H., Tewari, A.N., Sankhyan, S., Dubey, D.S., Mina, U., Singh, V.K., Jain, N., Bhatia, A. 2011. Directseeded rice: Potential, performance and problems - A review. Curr. Adv. Agric. Sci. 3:77-88.

Peng, Z.P., Huang, J.C., Yu, J.H., Yang, S.H., Li, W.Y. 2011. Effects of PP333 and nutrient elements applied on yields and root growth of rice. Chinese Agric. Sci. Bullet. 27:234-237. (in Chinese with English abstract)

Pouramir-Dashtmiana, F., Khajeh-Hosseinia, M., Esfahani, M. 2014. Improving chilling tolerance of rice seedling by seed priming with salicylic acid. Arch. Agron. Soil Sci. 60:1291-1302.

Shah, J. 2003. The salicylic acid loop in plant defense. Curr. Opin. Plant Biol. 6:365-371.

Sharifi, P., Aminpanah, H. 2010. Evaluation of eighteen rice genotypes in cold tolerance at germination stage. World Appl. Sci. J. 11:1476-1480.

Vardhini, B.V., Rao, S.S.R. 2003. Amelioration of osmotic stress by brassinosteroids on seed germination and seedling growth of three varieties of sorghum. Plant Growth Regul. 41:25-31.

Walia, H., Wilson, C., Condamine, P., Liu, X., Ismail, A.M., Close, T.J. 2007. Large-scale expression profiling and physiological characterization of jasmonic acid-mediated adaptation of barley to salinity stress. Plant Cell Environ. 30:410-421. 
Wang, B., Zeng, G. 1992. Effect of epibrassinolide on the resistance of rice seedlings to chilling injury. J. Plant Physiol. Mol. Biol. 19:53-60.

White, P.J., Broadley, M.R. 2003. Calcium in plants. Ann. Bot. 92:487-511.

Yang, S.J., Hosokawa, M., Mizuta, Y., Yun, J.G., Mano, J., Yazawa, S. 2001. Antioxidant capacity is correlated with susceptibility to leaf spot caused by a rapid temperature drop in Saintpaulia (African violet). Sci. Hort. 88:59-69.

Yoshida, S. 1981. Fundamentals in rice crop science. Int. Rice. Res. Inst., Los Baños, Laguna, Philippines.

Zheng, L.Y., Wu, W.G., Yan, C., Zhang, Y.H., Xu, Y.Z., Xu, R.M., Wang, H.Y., Cui, N., Chen, Z.Q. 2011. Effects of plant growth regulators on photosynthetic rate and yield components of rice. Crops 3:63-66.

\section{Electronic Supplementary Material (ESM)}

Electronic Supplementary Material (ESM) associated with this article can be found at the website of CRC at http://www.akademiai.com/content/120427/

Electronic Supplementary Table S1. Analysis of variance (F value) for the investigated parameters

Electronic Supplementary Table S2. Effects of exogenous spraying with plant growth regulators on plumule survival rate, shoot and root morphology of rice seedlings

Electronic Supplementary Table S3. Correlation coefficients among the investigated parameters

Electronic Supplementary Table S4. Squared cosines of the variables

Electronic Supplementary Figure S1. Survival rate (SR) of super rice plumules under different chilling-stress conditions (A) $11^{\circ} \mathrm{C}$, (B) $12{ }^{\circ} \mathrm{C}$, (C) $13{ }^{\circ} \mathrm{C}$, (D) $14{ }^{\circ} \mathrm{C}$, and (E) $15{ }^{\circ} \mathrm{C}$. SR = survived plumule / seed number) $\times 100$. Capped bars represent S.D $(n=3)$

Electronic Supplementary Figure S2. Effects of exogenous spraying of plant growth regulators on the (A) POD, (B) SOD, (C) MDA, and (D) proline contents of rice seedlings. Capped bars represent SD ( $\mathrm{n}=3$ ). FW $=$ fresh weight 